\title{
XLVIII. On the determination of coefficients of mutual induction by means of the ballistic galvanometer and earth-inductor
}

\section{R.H.M. Bosanquet}

To cite this article: R.H.M. Bosanquet (1887) XLVIII. On the determination of coefficients of mutual induction by means of the ballistic galvanometer and earth-inductor , Philosophical Magazine Series 5, 23:144, 412-420, DOI: 10.1080/14786448708628030

To link to this article: http://dx.doi.org/10.1080/14786448708628030

冓 Published online: 29 Apr 2009.

Submit your article to this journal $[\pi$

Џll Article views: 2

Q View related articles $\sqsubset$ 


\section{$\left[\begin{array}{ll}412 & ]\end{array}\right.$}

XLVIII. On the Determination of Coefficients of Mutual Induction by means of the Ballistic Galvanometer and Earth-Inductor. By R. H. M. BosanqueT*.

WY attention was drawn to this subject by the paper 11 recently read before the Society by Prof. Fostert. I observed at once that the appliances which I am in the habit of using afford a very simple solution of the problem.

The ballistic galvanometer has a resistance less than 2 B.A. units, and about 500 turns. I have three earth inductioncoils, all having a mean diameter of about half a metre, and the following constants. The resistances are approximate, as they vary so much with temperature. The wires are all cotton-covered copper.

\begin{tabular}{|c|c|c|c|c|}
\hline $\begin{array}{c}\text { Number of } \\
\text { turns. } \\
\text { N. }\end{array}$ & $\begin{array}{c}\text { Total effective } \\
\text { area. } \\
\log \text { NA. }\end{array}$ & $\begin{array}{l}\text { Mean circum- } \\
\text { ference. }\end{array}$ & $\begin{array}{c}\text { Approximate } \\
\text { resistance. } \\
\text { B.A. }\end{array}$ & $\begin{array}{l}\text { Wire. } \\
\text { B.W.G. }\end{array}$ \\
\hline 42 & $4 \cdot 97132$ & $167 \cdot 325$ & $\cdot 6$ & 16 \\
\hline 250 & $5 \cdot 74200$ & $166 \cdot 583$ & $10 \cdot 8$ & 20 \\
\hline 1000 & 6.36182 & $170 \cdot 005$ & 42 & 20 \\
\hline
\end{tabular}

The circular channels are turned in wooden rings framed together in many pieces. They were turned in the Royal Society's lathe in my laboratory. They are mounted so as to turn on vertical axes through half a revolution, in doing which they are reversed with respect to the horizontal component of the earth's magnetism, and so experience an electrical impulse equal to $2 \mathrm{NAH}$.

If the resistance of the circuit be $R$, a transfer of electricity then takes place, such that

$$
\mathrm{Q}_{0}=\frac{2 \mathrm{NAH}}{\mathrm{R}} \text {. }
$$

The various windings of the coils were measured with great care during the construction. The areas were calculated for each layer separately; and the above values of $\log \mathrm{NA}$ are probably certain to the fourth place of decimals.

There are two tangent-galvanometers, both on Helmholtz's pattern, having mean circumferences of exactly 1 metre. The one has 2 coils, the other 18 . The currents in them are measured by the formula

$$
\mathrm{C}=\mathrm{GH} \tan \theta \text {; }
$$

* Communicated by the Physical Society : read February 26, 1887.

† Phil. Mag. February 1887, p. 121. 
where $\log G$ has the values:-

$$
\begin{aligned}
& \text { No. of coils. } \log G \text {. } \\
& 2 \text {. . . . . . . } \cdot 24797 \\
& 18 \text {. . . . . . } \overline{1} 29373
\end{aligned}
$$

We can now proceed to the problem.

Two coils, P, S, are placed side by side, and a current passed through $\mathrm{P}$; then, on making the contact, a ballistic galvanometer in the circuit of $\mathrm{S}$ is deflected. The earth inductioncoil forms part of the circuit of $\mathrm{S}$.

So far we have the equations

$$
\begin{aligned}
& \mathrm{C}=\mathrm{GH} \tan \theta, \quad . \quad . \quad . \quad . \\
& \mathrm{Q}=\frac{\mathrm{MC}}{\mathrm{R}}, \cdot . \cdot .
\end{aligned}
$$

with reading $=\alpha$ minutes of arc.

If we now give the earth induction-coil a half turn, we have

$$
\mathrm{Q}_{0}=\frac{2 \mathrm{NAH}}{\mathrm{R}}, \text {. . . . . }
$$

with reading $=\beta$ minutes of arc.

$$
\text { Whence } \quad \begin{aligned}
\frac{\mathrm{Q}}{\mathrm{Q}_{0}} & =\frac{\mathrm{MG} \tan \theta}{2 \mathrm{NA}} \\
& =\frac{\alpha}{\beta}
\end{aligned}
$$

by the principle of the ballistic galvanometer. And

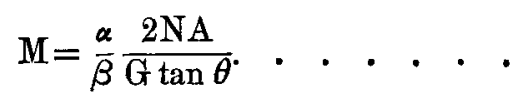

The 2 disappears from the numerator if the observation is made by reversal.

In order that $\mathrm{H}$ may be the same for the tangent-galvanometer and the earth induction-coil, it is necessary to remove the tangent-galvanometer and put the earth induction-coil in its place before making the observation $\beta$.

There are two classes of cases which cannot be treated by this most simple form of the method:-

(a) Where the quantity of electricity to be dealt with is too large for the galvanometer, even with the coil of highest resistance. And

(b) where the resistance of one of the coils to be determined is so great that no earth induction-coil could throw a sufficient quantity of electricity through it.

In both these cases we have to introduce a large resistance 
into the circuit $S$, after calibrating the galvanometer without it. The value of the deflection is then altered in the ratio of the change of resistance.

Let $\mathrm{R}$ be the total increased resistance,

$\mathrm{R}_{0}$ the resistance without the addition.

Then equations (2), (3), (4) become

$$
\begin{aligned}
& \mathrm{Q}=\frac{\mathrm{MC}}{\mathrm{R}}, \ldots . . . \\
& \mathrm{Q}_{0}=\frac{2 \mathrm{NAH}}{\mathrm{R}_{0}}, . . . \\
& \mathrm{M}=\frac{2 \alpha \mathrm{RNA}}{\beta \mathrm{R}_{0} \mathrm{G} \tan \theta^{*}} . . .
\end{aligned}
$$

The 2 disappears, as before, when reversal is employed.

An example of case $(a)$ is given later; where, in the second determination of my Gramme machine, a resistance of 1000 B.A. units was introduced into the secondary circuit, to moderate the deflection. The determination of the resistances, however, can hardly ever be accurate, as the copper earth induction-coil is liable to great alterations through change of temperature.

An example of case (b) would be afforded by the determination of such an induction-coil as the one by Apps, with high resistance S, mentioned in Prof. Foster's paper. In this case the galvanometer would be calibrated by the earth inductioncoil, the high resistance-coil then introduced, and the known values of $R, R_{0}$ employed in formula (7).

The determinations I have made are mostly of the mutual coefficients of the coils of my earth-inductors, placed close together. I have also made a couple of determinations of the coefficient of field-magnets and armature in my A Gramme machine.

The determination of February 21 was rather rough; the coils were placed together in their frames, but they could not be brought very near. The numbers are useful, as illustrating the increase of the discrepancy of Maxwell's formula, with the increase of $b$, the distance of the central planes. In fact, unless $b$ is small compared with the diameters, the formula is not properly applicable. Here it is about half either of the radii, and calculated and observed values are nearly as $4: 5$.

On February 22 the coils were dismounted and brought as close together as possible, $b$ being now between a quarter and a third of either of the radii. The calculated and observed values are nearly as $5: 6$. In order to see what part of the 
error was due to the dimensions of the section of the coils, the coefficient was then calculated by the more accurate formula referred to below; but the improvement is very slight. It appears that this formula does not in any way cure that defect, which arises from the distance of the central planes. So that in coils similar to mine we cannot expect to get nearer by calculation than the number last referred to, which is to the observed number nearly as $6: 7$.

On February 23 experiments were arranged with a view to test the consistency of the method, the coils examined being made primary and secondary alternately. Though the mode of observation does not admit of great accuracy, it appears that there is a systematic difference between the results of the two arrangements, amounting to about $1 \frac{1}{2}$ per cent. This I have not been able to explain. The coefficients of self-induction of the coils should have no influence; but that of the 250 will be very much greater than that of the 42 , and this is the only source of error that I can suggest. The number calculated by Maxwell's original formula is to the mean of observation nearly as $6: 7$.

In all the experiments difficulty was experienced in consequence of the continual fall of the battery-current. Without care in charging, and freshly charged cells, the experiments could hardly be made, as the fall of the current affects the galvanometer in the intervals.

Rowland's method of control, with a magnet and coil, was employed.

The determinations of the coefficient of the Gramme machine were very rough. In fact the fundamental equation (2) is not really applicable to the dynamo at all, except perhaps in the upper part of its range, where the current is, say, 10 amperes or more. For small currents do not do more than shake the subpermanent magnetism, which is considerable compared with the magnetism due to small currents. And in motion the machine makes use of this subpermanent magnetism, although it does not enter into the electrical coefficient of mutual induction.

The observations of Feb. 24 were very irregular ; it appeared as if the current sometimes shook the subpermanent magnetism and sometimes not. Still a mean was fairly deducible.

On Feb. 25 a stronger current was employed, and the observations were fairly regular; but this current, though it moves the subpermanent magnetism, is quite insufficient to reverse it as the reversal of a large current does; so that even here we do not get a representation of the whole effect. 
In the higher part of the range of the machine, say for unit-current (10 amperes), we can assume, without serious error, that the fundamental equation (2) holds. That being so, we can deduce the value of $M$ from the resistance and number of revolutions with which a stable current is produced.

It will be convenient to assume that all the coils of the armature are gathered up into two coils at right angles. Then, if one be parallel and the other perpendicular to the axis of the magnetic field, the determination of the coefficient of induction at rest affects only one of the coils, or half the armature.

Then, as to one of these coils, or half the armature :-In a half revolution the same effect is produced as if the exciting current were reversed, and a quantity of electricity passes,

$$
=\frac{2 \mathrm{MC}}{\mathrm{R}} \text {. }
$$

In a whole revolution $\frac{4 M C}{R}$ passes.

The same applies to the other half of the armature, so that altogether $\frac{8 \mathrm{MC}}{\mathrm{R}}$ passes in each revolution.

If there be $n$ revolutions per second, the quantity passing in $n$ revolutions = the current numerically, and this divides out, so that

$$
\mathrm{M}=\frac{\mathrm{R}}{8 n} \text {. }
$$

In an old paper of mine on Practical Electricity (Phil. Mag. xiv. p. 246) I find data from which, by interpolation, I obtain the corresponding values for this machine:-

$$
\begin{array}{ccl}
n^{\prime} \text { per minute. } & \text { R. }_{\mathbf{*}} & \text { C. } \\
840 & 10^{9} \times 5 \cdot 55 & 1=10 \text { amperes. }
\end{array}
$$

Whence $\mathrm{M}=10^{7} \times 4.95$.

The assumption made above is rough, but we cannot specialize further unless the distribution of the field is known. The two coils may then be supposed to be in any required proportion instead of being equal.

Regarding the coefficient as the product of the number of windings of armature and magnets, and of the magnetic induction common to both, due to unit-current, we can find the common magnetic induction in this case. There are 1700 turns in the armature, half of which count, and 234 turns on each of the four magnets, two of which receive each part of the common 
induction. Whence the common magnetic induction is

$$
\frac{10^{7} \times 4.95}{468 \times 850}=125 \text {. }
$$

This seems very small. But the dimensions of the armature are such that it can have hardly any core.

But I must not now pursue the subject of the dynamo.

The method of the earth induction-coil and ballistic galvanometer is susceptible of numerous applications. I have in my mind the direct determination of the capacity of a condenser, and a method following the lines of that used by Weber, for the determination of resistance. He employed earth induction-coils on this principle, though I do not know how they were arranged in detail. I cannot conceive how a tangent galvanometer could be employed for the ballistic work, as seems to be contemplated in Maxwell's account. I should determine the constant of the ballistic galvanometer for the purpose by a shunt comparison with a tangent galvanometer. I believe Mr. Glazebrook has done something of this kind in another case. In fact I have been through the work of such a method; but where there is a shunt to be verified, in this case $1: 10,000$, as well as other determinations of resistances, the errors of temperature are so troublesome to deal with, that in the present state of the subject I doubt whether it is worth while to spend much labour on it.

The numerical results of the experiments referred to are appended.

$$
\text { Coefficients of Induction of } 250 \text { and } 100 \text { coils. }
$$

Feb. 21. Distance between central planes, $b=13.97$ centims.

\begin{tabular}{|c|c|c|c|c|c|c|}
\hline $\begin{array}{l}\text { Arrange- } \\
\text { ment. } \\
250 \mathrm{P}\end{array}$ & $\begin{array}{c}a . \\
152^{\prime} \cdot 5\end{array}$ & $\begin{array}{c}\beta . \\
164^{\prime} \cdot 5\end{array}$ & $\begin{array}{c}\theta . \\
15^{\circ} 45^{\prime}\end{array}$ & $\begin{array}{c}\text { Galvano- } \\
\text { meter. } \\
18\end{array}$ & and & $\begin{array}{c}\text { M. } \\
10^{7} \times 7 \cdot 6903\end{array}$ \\
\hline
\end{tabular}
$\beta$ by half turn of 1000 coil.

${ }^{*}$ Calculation by Maxwell's original formula . . . $10^{7} \times 6 \cdot 164$

Feb. 22. Distance between central planes, $b=7.925$ centim. $\beta$ by half turn of 1000 coil.

Arrangement.

$250 \mathrm{P}$ $1000 \mathrm{~S}$ a.

$\beta$. $203^{\prime} \cdot 7 \quad 170^{\prime} \cdot$ $\theta$. $12^{\circ} 33^{\prime}$
Galvanometer. make and break
M. $10^{8} \times 1 \cdot 2593$

*Calculation by Maxwell's original formula . . . $10^{8} \times 1.070$

* Calculation by formula for dimensions of section of coils $10^{8} \times 1 \cdot 104$.

* New edition of Maxwell's 'Electricity and Magnetism,' vol. ii. pp. 314, 320 .

Phil. Mag. S. 5. Vol. 23. No. 144. May 1887. 2 F 
Data for this last formula :-

$$
\begin{array}{rrrr}
n & =1000 & n^{\prime}=250 \\
a & =27 \cdot 056 & & a^{\prime}=26 \cdot 512 \\
& \multicolumn{2}{c}{b=7 \cdot 925} \\
2 h=2 \cdot 18 & 2 h^{\prime}=.562 \\
2 k=5 \cdot 45 & 2 k^{\prime}=5 \cdot 77
\end{array}
$$

\begin{tabular}{|c|c|c|c|c|c|c|c|c|}
\hline Date. & Set. & $\begin{array}{c}\text { Arrange- } \\
\text { ment. }\end{array}$ & $a$. & $\beta$. & $\theta$. & $\begin{array}{l}\text { Galvano } \\
\text { meter. }\end{array}$ & $\begin{array}{c}\text { Make \& break } \\
\text { or reversal. }\end{array}$ & M. \\
\hline \multirow[t]{2}{*}{ Feb. 23.} & 1 & $\begin{array}{r}42 \mathrm{P} \\
250 \mathrm{~S}\end{array}$ & $202 \cdot 2$ & $142^{\prime}$ & $3 i 56$ & 2 & m. b. & $10^{6} \times 5.9390$ \\
\hline & 2 & $250 \mathrm{P}$ & $88 \cdot 2$ & 173 & 4420 & 18 & rev. & $\times 6.1075$ \\
\hline \multirow[t]{3}{*}{ Feb. 24 . } & 1 & ........ & 86.5 & 175 & $4355 \cdot 5$ & $\ldots$ & $\ldots$ & $\times 6.0030$ \\
\hline & 2 & ....... & $85 \cdot 2$ & 175 & 435 & $\ldots$ & $\ldots$ & $\times 60893$ \\
\hline & 3 & $\begin{array}{r}42 \mathrm{P} \\
250 \mathrm{~S}\end{array}$ & $190 \cdot 2$ & $144 \cdot 7$ & 2943 & 2 & m. b. & $\times 5.9862$ \\
\hline
\end{tabular}

Coefficients of Induction of 42 and 250 coils.

Distance between central planes, $b=6.35$ centim. $\beta$ by half turn of 1000 coil, in $\mathbf{S}$, throughout.

Calculation by Maxwell's original formula . $10^{6} \times 5 \cdot 275$

Comparison of arrangements :-

Feb. 23. $110^{6} \times 5.9390$

"24. $3 \times 5.9862$

$$
\begin{array}{rr}
42 \mathrm{P} & 250 \mathrm{P} \\
250 \mathrm{~S} & 42 \mathrm{~S}
\end{array}
$$

\section{$250 \mathrm{P}$}

Mean $\times 5.9626$

Feb. 23. $210^{6} \times 6.1075$

"24. $1 \times 6.0030$

$" \quad 2 \times 6.0893$

Mean $\times 6.0666$

\begin{tabular}{|c|c|c|c|c|c|c|}
\hline & $\begin{array}{c}\alpha . \\
146^{\prime}\end{array}$ & $\begin{array}{c}\beta . \\
179^{\prime}\end{array}$ & $\begin{array}{c}\theta \\
27^{\circ} 11^{\prime}\end{array}$ & $\begin{array}{c}\text { meter. } \\
18\end{array}$ & $\begin{array}{c}\text { Amperes. } \\
\cdot 181\end{array}$ & $\begin{array}{c}\text { M. } \\
10^{7} \times 1.858\end{array}$ \\
\hline & & $\ldots$ & ...... & $\ldots$ & - & \\
\hline & 113 & 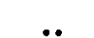 & ...... & ... & $\ldots$ & \\
\hline
\end{tabular}

Mean of both arrangements $10^{6} \times 6.0146$.

Determinations of Coefficient of Induction of Dynamo Fieldmagnets and Armature. (A Gramme.)

Feb.24. $\mathrm{P}$ field-magnets, with two bichromates and 10 B.A. units.

S armature, ballistic galvanometer, and 1000 coil. By reversal. 
Feb. 25. P field-magnets, with two bichromates.

S armature, ballistic galvanometer, and 1000 coil, with and without 1000 B.A. units, so that

$$
\mathrm{R}=1045, \quad \mathrm{R}_{0}=45 \text {. }
$$

By reversal.

$\begin{array}{cccccc}a . & \beta . & \theta . & \text { meter. } & \text { Amperes. } & \text { M. } \\ 179^{\prime} \cdot 5 & 179^{\prime} & 39^{\circ} 24^{\prime} & 2 & 2 \cdot 54 & 10^{7} \times 3.685 \\ & & \text { By formula } \mathrm{M}=\frac{\mathrm{R}}{8 n} & 10 \cdot 0 & 10^{7} \times 4.95\end{array}$

\section{ADDENDUM.}

March 5. Supplementary Notes.

1. Calculation of coefficients by the elliptic integral table in the new edition of Maxwell, combined with the formula for approximation to the effect of the sections of the coils.

I have now calculated the experiments of Feb. 22 and Feb. 23-24 by this method, which is the most complete that exists, short of calculating all the single combinations of circles in the two coils. The accordance with experiment is somewhat better, but still far from close.

Observed.

Feb. $\quad 22 . \quad 10^{8} \times 1.259$

, 23-24. $10^{6} \times 6.015$
Calculated.

$10^{8} \times 1 \cdot 176$

$10^{6} \times 5 \cdot 585$

2. Simple formula for approximate calculation of the coefficient.

Assume that the field in $a$ due to $A$ is everywhere the same as at the centre of $a$. Then the total lines of force for unit current are

$$
\pi a^{2} \times \frac{2 \pi \mathrm{A}^{2}}{\left(\mathrm{~A}^{2}+b^{2}\right)^{\frac{3}{2}}}
$$

where $b$ is the distance between the planes of the circles, or, if $\frac{A}{b}=\tan \theta$, this becomes

$$
\frac{2 \pi^{2} a^{2} \sin ^{3} \theta}{\mathrm{A}}
$$

which is simpler to calculate than Maxwell's approximate formula.

The following is the comparison of this formula with observation.

Observed.

Feb. 21. $10^{7} \times 7 \cdot 690$

22. $10^{8} \times 1 \cdot 259$

", 23-24. $10^{6} \times 6.015$

2 F 2
Oalculated. $10^{7} \times 8.991$ $10^{8} \times 1 \cdot 133$ $10^{6} \times 5 \cdot 036$ 
3 . Course of values of the coefficient of field-magnets and armature of a dynamo.

The numbers stated in the paper may possibly be misleading, as it is not sufficiently explained that the number determined from the motion of the machine, $\left(\frac{\mathrm{R}}{8 n}\right)$, is not of the same nature as the two results of determinations made at rest, which precede.

The number determined from $\left(\frac{\mathrm{R}}{8 n}\right)$ is necessarily infinite when the current is evanescent, if there is any retention of magnetism in the machine, and diminishes continually as the current increases. The following corresponding values of this coefficient and current are given by the data referred to in the paper.

$\begin{array}{rr}\text { Coefficient. } & \text { Ourrent in am } \\ 10^{7} \times 7 \cdot 054 & 3.8 \\ \times 6 \cdot 250 & 5.5 \\ \times 5.600 & 7 \cdot 6 \\ \times 4.732 & 10.5\end{array}$

XLIX. The Effects of Percussion and Annealing on the Magnetic Moments of Steel Magnets. By William BRown, Thomson Experimental Scholar, Physical Laboratory, University of Glasgow*.

\section{PART II.}

TN Part I. of this paper, which appeared in the March I number, certain proliminary results were given, showing the effects of percussion on the magnetic moments of steel magnets. In the present communication these effects are considered in greater detail, with tables giving the results of an extended series of experiments, and the question of annealing is treated with respect to exact measurements of the annealing temperature.

The steel experimented on in this case was furnished to Sir William Thomson for experimental purposes by two different steel-makers.

The following Table gives approximately the relative percentage proportions of all the substances found in the steel, the quantities in specimen I. being taken as unity. They are taken, not from analyses of the particular pieces experimented on, but from a general analysis of the sample in each case.

* Communicated by Sir William Thomson. 